A TWIN.BALLOON AIRSHIP.

A new type of dirigible balloon is in course of construction in London, which is the invention of Mr. L. J. Andersen. The principal feature of this latest aerostat is that two balloons, placed side by side, of identical shape and capacity, are employed to lift the vessel. It is maintained by the inventor that by this system of twin balloons it is possible when flying to maintain a straighter and more even course, while greater facilities in regard to the steering are available than by the employment of only one gas bag. Already the inventor has constructed a model, to scale, of his ultimate airship for the purpose of experiments. In this model the balloons are each 7 feet in length. So successful were the experiments, that the inventor is now constructing a full-sized vessel. The balloons are elliptical in shape, and will measure 70 feet in length by 27 feet diameter at the widest part. They will each be of approximately 27,000 feet of hydrogen gas, thus giving them a lifting power of 4,000 pounds.

The framework, or deck, of the vessel will measure 75 feet in length, and is to be constructed of bamboo. Another feature of the craft will be the employment of three propellers. The main propeller will be placed at the stern, together with the rudder. By an ingenious arrangement, however, the pitch of this driving propeller may be varied from the deck of the vessel as desired, the object of which is to use it as an auxiliary though powerful rudder, for maintaining or altering the ship's course according to the exigencies that arise. The two subsidiary propellers are placed at the bow and stern of the deck respectively, and are intended to supplement the driving power of the mechanism. The whole of the machinery is placed between the two balloons; for the inventor holds that by this design the improvement of the steering possibilities and the maintenance of a straight course are materially increased. The motion of the propellers and their design are entirely new, coinciding as nearly as possible to a reciprocatory motion, so that the nearest approach to the motion of a bird's wing is obtained. The propellers are to measure 30 feet in diameter.

The motive power is to be supplied from a 50 horsepower electric motor. and the inventor antici pates that a speed varying from 14 to 20 miles an hour in fair weather wil be attained. The total weight of the vessel will be 3,000 pounds, which leaves a balance of 1,000 pounds, after deducting this weight from the lift ng capacity of the aerostat, for the carriage of passengers, ballast, etc. It is hoped that the balloon will be ready for trials some time this year, and its total cost will approximate $\$ 10,000$

\section{THE WINDOWS OF THE} SEA.

Some sixteen years ago when watching the play of fishes along the kelp beds of the Santa Catalina group, the writer described to the boatman a plan for using a "sea window" he had employed on the Flor ida reef, also the water box for collecting; and from this suggestion has grown an industry illustrated at Avalon by a fleet of socalled glass-bottom boats, whose owners or captains whose owners or captains shores of this place much as do hackmen in large cities, or gondoliers in Venice. The writer had a boat in Florida which had a well 4 hy 6 feet, boarded at the bottom, with perforations, after the fashion of all the smacks at that time, which carried their catch in wells. But the central portion of this well was covered with glass, so that as the boatman poled along over the coral reef, every object could be seen and secured by diving or otherwise. Used with this was an ordinary water box, one end being left open, the other covered with glass, which when placed upon the water, made everything plain and discernible.

The Catalina boats are built on this plan. A well in

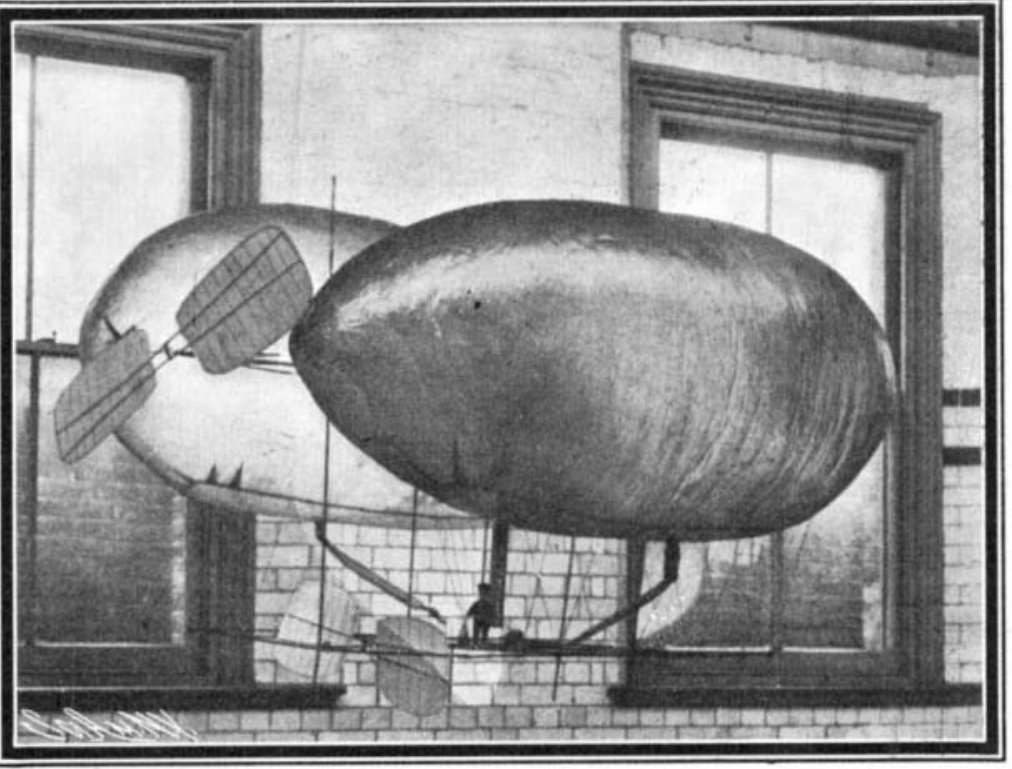

a CATAMARAN AIRBHIP. the landsman, to whom it was a remarkable novelty. The kelp beds of Santa Catalina lend themselves particularly to this, being in smooth water in Avalon Bay and very beautiful. The first glass-bottom boat was propelled by a man who sat forward and rowed, also acting as a guide, pointing out the wonders of the deep with no sluggish imagination. As the fame of the glass-bottom boat spread afar, new and timeglass-bottom boat spread afar, new and timemotor glass-bottom boat appeared. This was a catamaran with a house on deck and a screw and engine astern; but it promptly sank, and no one could be induced to enter the box; indeed, there was always a certain percentage of "riders and seers" who were suspicious of the "window" What if the glass should break?-iorgetting that water would not rise in tho well higher than it was on the outside.

The evolution of the glass-bottom boat continued, and inally some venturesome spirit built a large power boat with a commodious well. which carried successfully a large number of pass $\epsilon$ ngers. This boat is here shown just before launching and afloat She was of peculiar build, being very flat, so that she could pass over the floating kelp and run in the shallowest water. As a propeller or screw would tangle in the kelp, this feature was avoided by using old-fashioned side paddle-wheels made very shallow, so that they just caught the water and did not catch the weed. The boat represents for the manner described is used, but instead of having a perforated wooden bottom the latter is all glass and the well empty, there being no occasion to hold or keep the specimens; the design is merely to see them The success of this scheme was at once apparent, and many men built boats. Old sailors, who had been masters of ships, now became captains of "glass-bottom boats," while their runners gathered in the street and shouted the varied attractions of the craft. The first glass-bottom boat was a large flat yawl or barge capable of holding twelve people, possibly more. The well rose about as high as one's knees, and was eight or ten feet in length; the passengers, leaning their elbows on the cushioned rim of the well, literally gaz ing through a window into the ocean, when ever object to a great depth became distinct, affordirg a beautiful vista of submarine scenery, appreciated by the present the perfection of the glass-bottom boat, which 1s, in a way, a liberal education in marine zoology, affording as it does opportunities to observe rare and singular objects.

The Death of Henry Carrington Bolton.

H. Carrington Bolton, well known for his chemical bibliographies and chemical investigations, recently passed away. An article of his in the American Chemist, 1876, exempliffed in telling words one of the great aims of his life, with the fruitful accomplishment of which all are familiar:

"So rapid are the strides made by science in this progressive age and so boundless is its range, that those who view its career from without find grea difficulty in following its diverse and intricate path ways, while those who have secured a footing within the same road are often with and would fain retire from the unequal contest. It is not surprising, then, that those actually contributing to the advancement of science, pressing eagerly up ward and onward, should neglect to look back upon the labors of those who precede them ind should sometimes lost: signt. of the obligations which sci ence owes to forgotten generations." His numerous contributions to and intinate knowledge of the his cory of chemistry, his gentle and generous sympathy, aided and stimulat ed many active in research or technical applications of chemistry. His monu mental bibliographies put out by the Smithsonian Institution are masterpieces.

Some irtaresting experiments process have been in prog ress at Pontymister Works, near Newport, Englan. Investigation has result ed in the discovery that by ine use of a secret a : loy, steel suitable tor mak ing tools can be produced from Siemens steel, in stead of only from crucible steel. The result is that a considerable saving is effected in the cost of manufacture. Should the ex periment be successful, it is anticipated that a new industry will be created, and the whole system of steel manufacture revo lutionized. 